\title{
Sistem Informasi Administrasi Berbasis Web di Bagwatpers Biro Sdm Polda Kepri
}

\author{
Atman Lucky Fernandes ${ }^{1}$, Nofri Yudi Arifin², Ajat Sudrajat ${ }^{3}$ \\ ${ }^{1,2}$ Universitas Ibnu Sina; Jalan Teuku Umar - Lubuk Baja, Batam, Kepulauan Riau \\ ${ }^{3}$ Program Studi Teknik Informatika, Universitas Ibnu Sina, Batam \\ e-mail: *1.
}

\begin{abstract}
Abstrak
Penelitian ini bertujuan untuk melakukan perancangan, pengujian dan penerapan sistem informasi administrasi di Bagwatpers Biro SDM Polda Kepri maka administrasi pengolahan data kenaikan gaji berkala, biaya perjalanan dinas mutasi, penetapan status gugur, tewas dan meninggal dunia biasa personel, pemenuhan perumahan juga tanda jasa dan tanda kehormatan personel agar tersedianya sistem informasi administrasi yang dapat mempermudah petugas upaya perbaikan masalah yang terkait dengan pengolahan data informasi kelengkapan pengisian administrasi masih menggunakan pengisian data di dalam formulir dan dikelola dengan aplikasi Microsoft office word sehingga pencarian data terasa lambat dan memakan waktu. Metode perancangan menggunakan metode system development lifce cycle dengan tahapan enam yaitu perencanaan, analisis, desain, implementasi, pengujian, dan perawatan. Sedangkan pemodelan yang digunakan menggunakan Unified Modeling Language (UML) yang terdiri dari yaitu use case diagram, activity diagram, sequence diagram dan class diagram. Sistem Informasi Administrasi Berbasis Web di Bagwatpers Biro SDM Polda Kepri berbasis web yang menggunakan Bahasa pemrograman PHP dan database MySQL sebagai pengolahan data administrasi. Hasil penelitian ini diharapakan dapat memenuhi kebutuhan petugas serta betapa pentingnya aplikasi pengolahan data data kenaikan gaji berkala, biaya perjalanan dinas mutasi, penetapan status gugur, tewas dan meninggal dunia biasa Personel, pemenuhan perumahan juga tanda jasa dan tanda kehormatan Personel untuk mendukung kesan bahwa sistem berjalan dengan baik, sehingga petugas terbantu dalam pengelolaan data administrasi. Untuk mendukung sistem yang ada maka diperlukan peningkatan sumber daya manusia, yaitu sumber daya dalam pengoperasian sistem dan mampu merawat, memelihara sistem tersebut dengan baik dan menambahkan aplikasi yang dapat memberikan kesimpulan dalam bentuk bentuk dashboard.
\end{abstract}

Kata kunci- Sistem Informasi, Administrasi, SDLC, Unified Modeling Language (UML), PHP, MySQL, Bagwatpers Biro SDM Polda Kepri.

\begin{abstract}
This study aims to design, test and implement an administrative information system at the Bagwatpers HR Bureau of the Riau Islands Regional Police, the administration of processing data for periodic salary increases, official travel costs, mutations, determining the status of death, death and death of ordinary personnel, housing fulfillment as well as service marks and signs. honor personnel so that the availability of an administrative information system that can make it easier for officers to repair problems related to processing information data completeness of administrative filling still uses data entry in forms and is managed with Microsoft office word applications so that data search feels slow and time consuming. The design method uses the system development life cycle method with six stages, namely planning, analysis, design, implementation, testing, and maintenance. While the modeling used using
\end{abstract}


Unified Modeling Language (UML) which consists of use case diagrams, activity diagrams, sequence diagrams and class diagrams. Web-Based Administrative Information System at Bagwatpers HR Bureau of the Riau Islands Police is web-based that uses PHP programming language and MySQL database as administrative data processing. The results of this study are expected to meet the needs of officers and the importance of data processing applications for periodic salary increases, official travel costs, mutations, determination of the status of death, death and ordinary death of personnel, fulfillment of housing as well as marks of service and honor of personnel to support the impression that the system is running. properly, so that officers are assisted in managing administrative data. To support the existing system, it is necessary to increase human resources, namely resources in operating the system and being able to maintain, maintain the system properly and add applications that can provide conclusions in the form of a dashboard.

Keywords - Sistem Informasi, Administrasi, SDLC, Unified Modeling Language (UML), PHP, MySQL, Satuan Brimob Kepolisian Daerah Kepulauan Riau, Batalyon A Pelopor diBagminpers

\section{PENDAHULUAN}

Teknologi pada sistem informasi saat ini mempermudah pemrosesan informasi yang dibutuhkan sehingga informasi yang disebarkan dapat lebih mudah, jelas, cepat dan lengkap, mempengaruhi bidang administrasi. Saat ini penggunaan teknologi banyak dimanfaatkan sebagai sistem informasi, salah satunya adalah dengan menggunakan teknologi Web, informasi dapat diakses tanpa adanya batasan ruang dan waktu seperti halnya dalam metode pemograman dalam membangun sebuah aplikasi menggunakan komputer sebagai alat dalam menyelesaikan pekerjaan. (Dedi dkk., 2019)

Kemajuan teknologi pada masa kini telah berkembang dengan sangat pesat. Kemajuan ini dapat dilihat dari banyaknya penemuan (invention) maupun inovasi (inovation) yang ada. Penemuan berarti proses pembuatan teknologi yang benar-benar baru yang belum ada sebelumnya, sedangkan inovasi merupakan proses memperbarui teknologi yang sudah ada guna memperbaiki kelemahan teknologi ataupun menambahkan fungsi pada teknologi tersebut. Baik penemuan maupun inovasi teknologi telah menimbulkan pengaruh pada masyarakat sehingga terjadi perubahan diberbagai bidang kehidupan, kemajuan teknologi tersebut menjadikan motivasi bagi suatu instansi untuk meningkatkan pelayanannya dan salah satu diantaranya yaitu instansi Kepolisian Negara Republik Indonesia (Sulistiyarini \& Sabirin, 2018).

Dengan berkembang pesatnya teknologi saat ini, Kepolisian Daerah Kepulauan Riau (Polda Kepri) merupakan perpanjangan tangan langusng dari Markas Besar Kepolisian Negara Republik Indonesia (Polri) yang merupakan satuan pelaksanaan utama kewilayahan yang bertugas menyelenggarakan tugas Polri pada tingkat kewilayahan yaitu Kepolisian Daerah yang membawahi Kepolisian Resor (Perpol Nomor 14 Tahun 2018 tentang Revisi Perkap Nomor 22 Tahun 2010 tentang Struktur Organisasi Tata Kerja Tingkat Kepolisian Daerah)

Didalam pelaksanaan Polda dibantu oleh beberapa Biro, Direktorat dan Bidang pada satuan kerja (Satker) yang bertugas memelihara keamanan dan ketertiban masyarakat yang meliputi bidang perlindungan, pengayoman, pelayanan dan penegakan hukum kepada masyarakat di wilayah Kepulauan Riau yang kini jabatan Kapolda Kepri dipimpin oleh Irjen Pol Dr. Aris Budiman, M.Si.

Kantor Bagian Perawatan Personel (Bagwatpers) Biro SDM Polda Kepri merupakan satuan kerja yang bertugas menyelenggarakan administarsi untuk para Personel dan staff dalam kesatuan Polda Kepri. Dimana pengelolaan data pelayanan masih bersifat konvensional dan masih menggunakan pengisian data formulir secara manual seperti Kenaikan gaji berkala Personel Polda Kepri dan Jajaran, Biaya Perjalanan Dinas Mutasi, Penetapan Status Gugur, 
Tewas dan Meninggal Dunia Biasa Personel, Pemenuhan Perumahan bagi Personel Polda Kepri dan Jajaran, Tanda Jasa dan Tanda Kehormatan Personel dan dibantu dengan pengelolaan data menggunakan aplikasi Microsoft Office word dan excel.

Penyimpanan berkas yang telah di isi di dalam formulir yang telah diisi juga tidak tersimpan dengan baik masih menggunakan penyimpanan secara manual sehingga dalam pencarian data terasa lambat dan memakan waktu yang cukup lama dan ini juga akan menghambat dalam pembuatan dokumen administrasi bagi Personel Kepolisian dan staff.

Berdasarkan permasalahan di atas, maka penulis tertarik untuk merancang suatu sistim administrasi guna untuk mengatasi permasalahan tersebut dan mengangkat judul skripsi yaitu "Sistem Informasi Administrasi Berbasis Web di Bagwatpers Biro SDM Polda Kepri ". Penelitian ini menggunakan metode System Development Life Cycle (SDLC) yang meliputi Requirement Analysis (analisa kebutuhan), Design (perancangan), Implementation (pengkodean), Verification (pengujian), dan Maintenance (pendukung). Sedangkan untuk pemodelan desainnya menggunakan Unified Modeling Language (UML) adalah alat perancangan sistem yang berorientasi pada objek.

Diharapkan dengan system ini dapat memberikan solusi dan alternative aplikasi dalam mensukseskan administrasi dan pelaporan di Bagwatpers Biro SDM Polda Kepri.

\section{METODE PENELITIAN}

Penelitian ini menggunakan desain memodelkan Unified Modeling Language (UML) dengan pendekatan metode pengembangan metode SDLC.Unified Modeling Language (UML) adalah sebuah bahasa pemodelan yang telah menjadi standar dalam industri software untuk visualisasi, merancang, dan mendokumentasikan sistem perangkat lunak (Ropianto, 2016).

UML mempunyai sejumlah elemen grafis yang bisa dikombinasikan sebagai berikut:

1. Use Case Diagram

2. Activity Diagram

3. Sequence Diagram

4. Class Diagram

Langkah-langkah dalam melakukan Tahapan SDLC yaitu:

1. Perencanaan

Tahap ini hal yang pertama dilakukan adalah melakukan observasi langsung ke tempat lokasi penelitian dan melakukan wawancara dan melihat apa saja yang terjadi untuk memberikan gambaran sistem yang berjalan saat ini.

2. Analisis

Dalam tahap analisis ini, digunakan oleh analis sistem:

1. Membuat keputusan apabila sistem saat ini mempunyai masalah atau sudah tidak berfungsi secara baik dan hasil analisisnya digunakan sebagai dasar untuk memperbaiki system;

2) Mengetahui ruang lingkup pekerjaannya yang akan ditanganinya;

3) Memahami sistem yang sedang berjalan saat ini;

4) Mengidentifikasi masalah dan mencari solusinya.

3. Perancangan

Tahap perancangan sistem mempunyai dua tujuan utama yaitu:

1) Memberikan gambaran secara umum tentang kebutuhan informasi kepada pemakai sistem secara logika;

2) Memberikan gambaran yang jelas dan rancang bangun yang lengkap kepada pemrogram komputer dan ahli-ahli teknik lainnya. 


\section{Implementasi}

Implementasi sistemadalah tahap meletakkan sistem supaya siap dioperasikan

\section{HASIL DAN PEMBAHASAN}

Pembuatan sistem informasi administrasi di Bagwatpers Biro SDM Polda Kepri menggunakan langkah-langkah dari metode SDLC sebagai berikut.

\subsection{Perencanaan}

Fase perencanaan (Planning) merupakan sebuah proses awal untuk memahami sebuah sistem harus dibangun. Tahap ini penulis merancang sistem yang cocok dengan masalah yang ada. Perencanaan dimulai dari merancang fitur yang akan diterapkan di dalam sistem. Fitur-fitur tersebut diantaranya adalah desain sistem informasi, daftar dashboard sistem, daftar pangkat, status keluarga dan data kenaikan gaji berkala Personel polda kepri dan jajaran, biaya perjalanan dinas mutasi; penetapan status gugur, tewas dan meninggal dunia biasa Personel; pemenuhan perumahan bagi Personel polda kepri dan jajaran dan tanda jasa dan tanda kehormatan Personel yang menjadi data pada sistem yang akan dibangun menyimpan data sistem informasi administrasi di Bagwatpers Biro SDM Polda Kepri

\subsection{Analisis Kebutuhan}

Merupakan tahap menguraikan seluruh kebutuhan yang digunakan untuk menggambarkan kebutuhan secara detail dengan tujuan untuk menghasilkan sesuatu yang baru atau memperbarui 1. Pengolahan Data

Menganalisa mengenai penelitiannya pada perancangan sistem informasi administrasi di Bagwatpers Biro SDM Polda Kepri. Dan penulis juga menemukan identifikasi masalah yang menjadi tolak ukur kekurangan atas sistemnya yang sedang berjalan pada saat ini, sehingga penulis ingin melakukan suatu perancangan sistem informasi administrasi di Bagwatpers Biro SDM Polda Kepri yang mana dimulai dari analisa data primer maupun data sekunder, membuat perancangan desain sesuai dengan menyesuaikan kebutuhan pengguna dan pengujian aplikasi sistem informasi administrasi di Bagwatpers Biro SDM Polda Kepri.

\section{Analisis Sistem}

sistem informasi yang utuh kedalam bagian-bagian komponennya dengan maksud untuk mengidentifikasikan dan mengevaluasi permasalahan-permasalahan, kesempatan dan hambatanhambatan yang terjadi dan kebutuhan yang diharapkan sehingga dapat diusulkan perbaikanperbaikan.

3. Analisis Sistem Informasi (ASI)

Pada aliran sistem yang di usulkan tidak merubah aliran data dalam pengelolan administrasi di Bagwatpers Biro SDM Polda Kepri, hanya pada sistem yang saat ini menggunakan aplikasi Microsoft office excel dengan penelitian perancangan administrasi di Bagwatpers Biro SDM Polda Kepri berbasis web pengolahan data bisa di akses secara online dan dokumen pengolahan administrasi bisa dicek oleh kabag dan karo. 


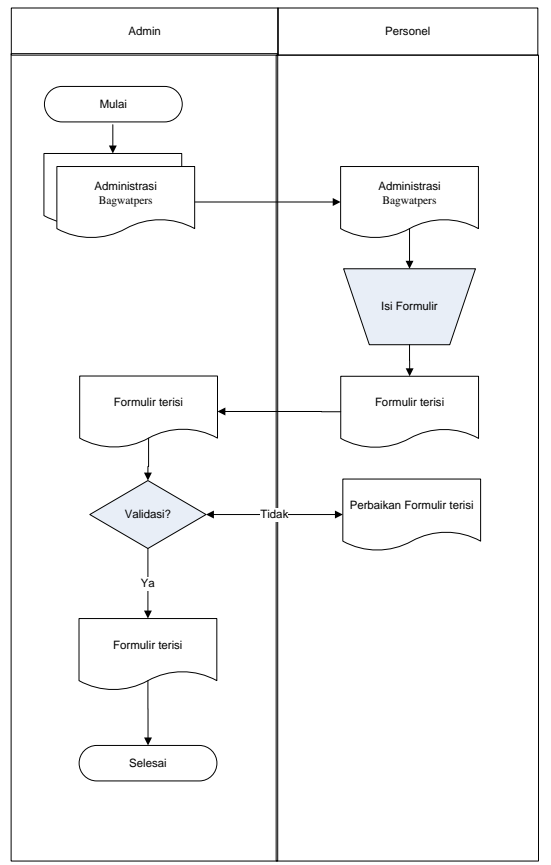

Gambar 1. ASI Saat Ini

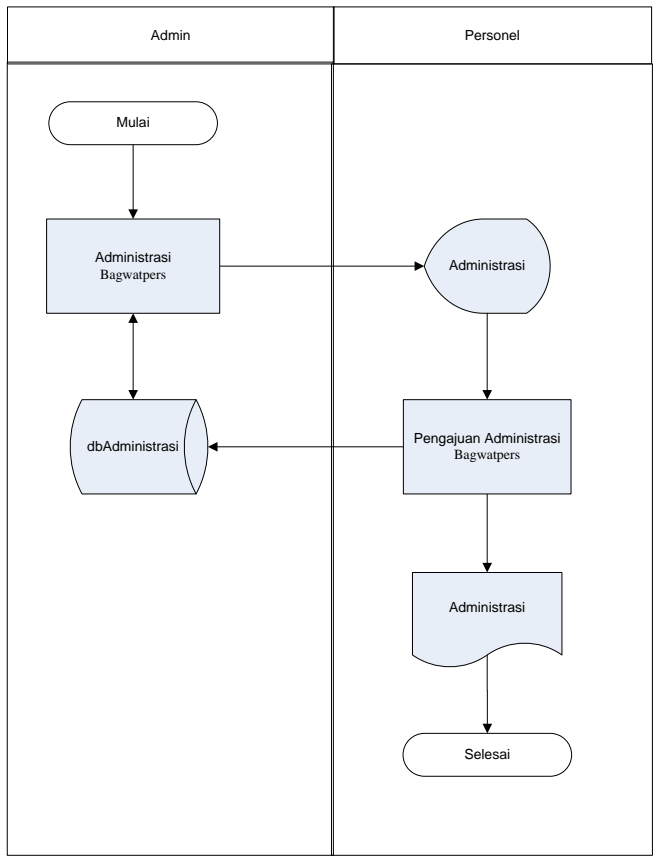

Gambar 2. ASI Yang diusulkan

4. Analisis Kebutuhan Fungsional

Kebutuhan fungsional merupakan tahap perancangan pola aliran informasi yang meliputi perancangan diagram dan aliran informasi yang di representasikan dengan menggunakan Unified Model Language.

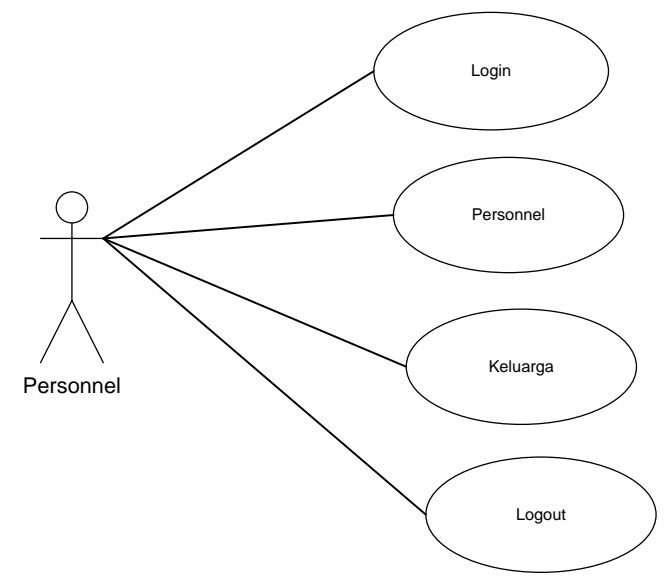

Gambar 3. Use Case Diagram Personel

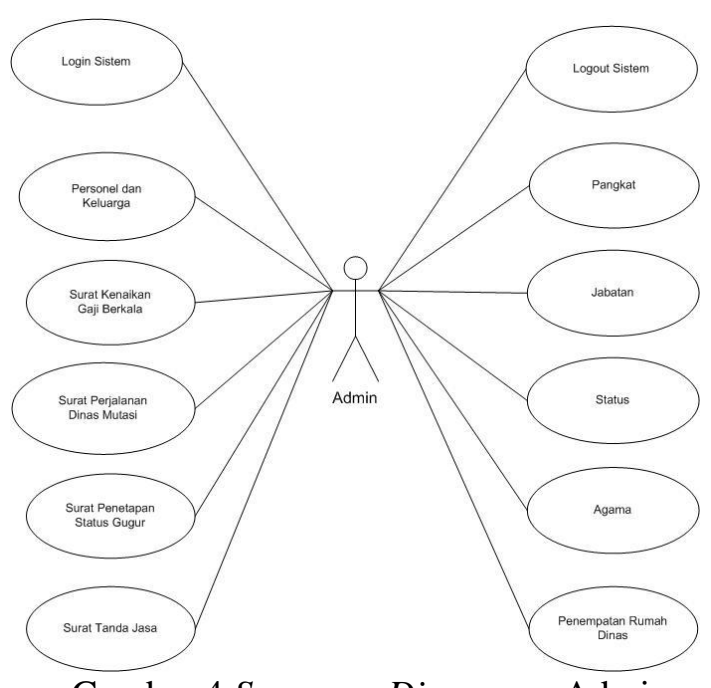

Gambar 4 Sequence Diagram - Admin 


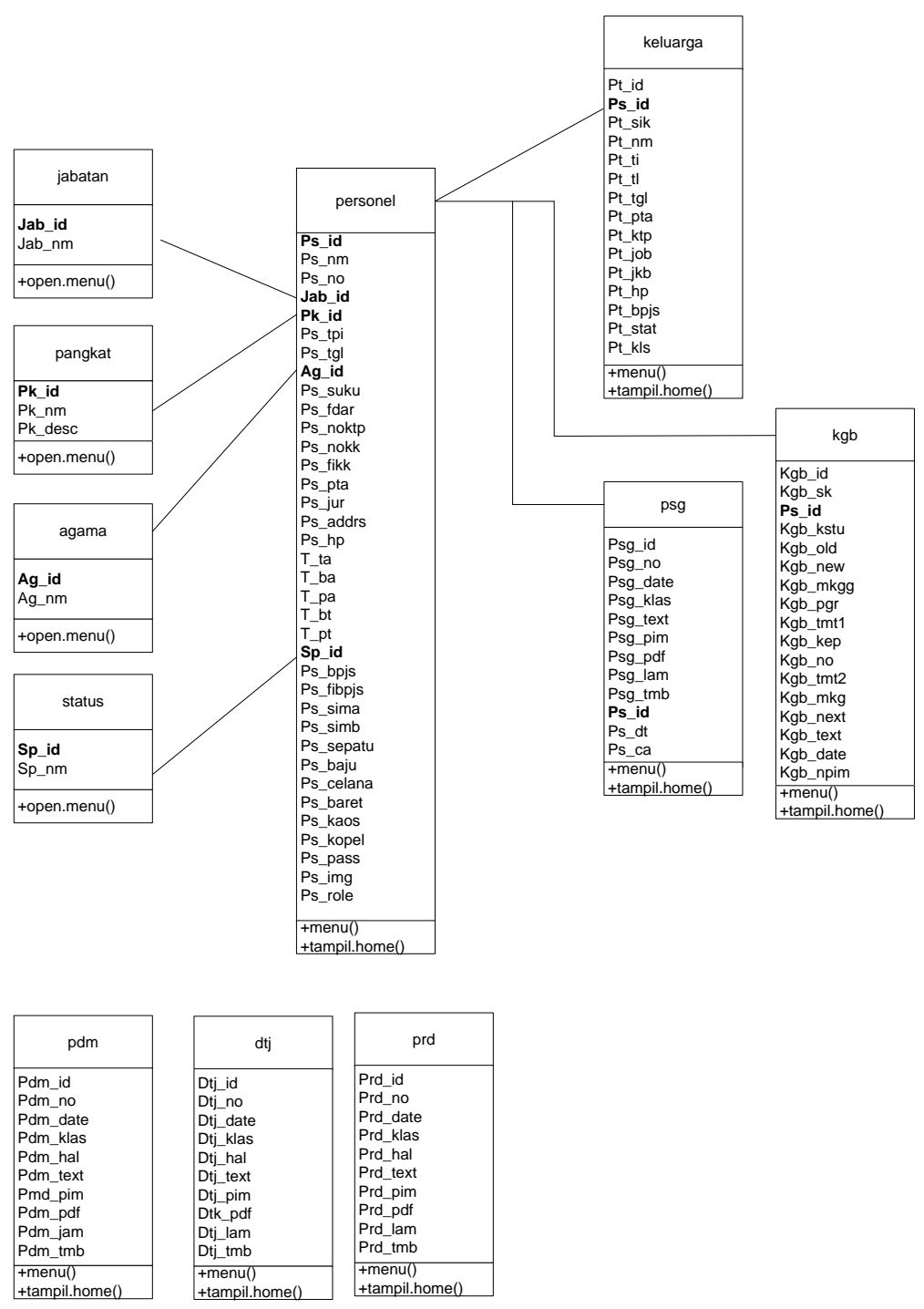

Gambar 5 Class Diagram - Aplikasi

\subsection{Desain Sistem}

Desain atau perancangan basisdata merupakan perancangan yang dibuat untuk mengambarkan tentang basisdata yang akan digunakan pada aplikasi yang akan dibangun. Perancangan basisdata yang akan dijelaskan antara lain mengenai skema relasi dan struktur tabel.

Tabel 1 Tabel Aplikasi Admininstrasi

\begin{tabular}{|c|l|l|}
\hline No & Nama Tabel & Keterangan \\
\hline 1 & Agama & Untuk menyimpan data agama \\
\hline 2 & Jabatan & Untuk menyimpan data jabatan \\
\hline 3 & Keluarga & Untuk menyimpan data keluarga \\
\hline 4 & Pangkat & Untuk menyimpan data kepangkatan \\
\hline 5 & Personel & Untuk menyimpan data Personel \\
\hline 6 & Status & Untuk menyimpan status \\
\hline 7 & PRD & Untuk menyimpan data perumahan Personel \\
\hline
\end{tabular}




\begin{tabular}{|c|l|l|}
\hline 8 & DTJ & Untuk menyimpan data tanda jasa \\
\hline 9 & KGB & Untuk menyimpan data kenaikan gaji berkala \\
\hline 10 & PSG & Untuk menyimpan data status gugur \\
\hline 11 & PDM & Untuk menyimpan data perjalan dinas mutasi \\
\hline
\end{tabular}

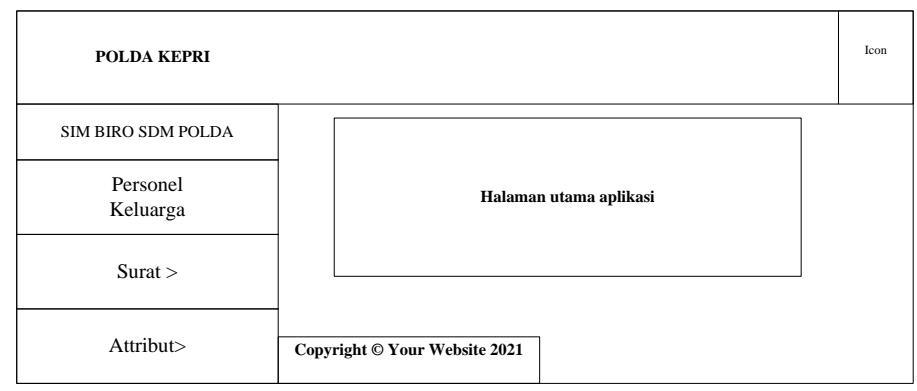

Gambar 6 - Rancangan Admin

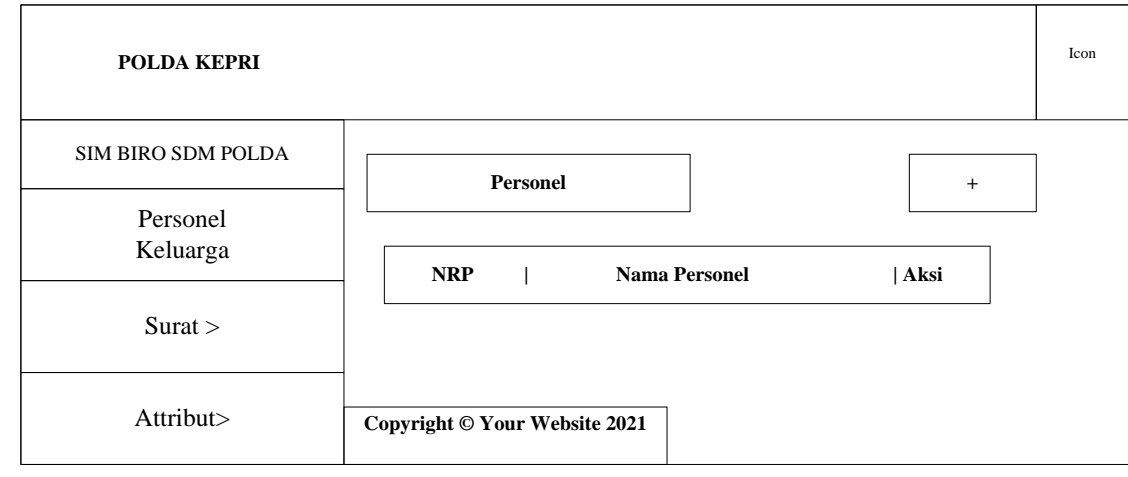

Gambar 7 - Rancangan Personnel

\subsection{Pengujian}

Pengujian dilakukan pada proses pengembangan sistem yakni pengujian kode program (coding). Pengujian black box dilakukan untuk menguji apakah sistem yang dikembangkan sesuai dengan apa yang tertuang dalam spesifikasi fungsional sistem. Black box juga digunakan untuk menguji fungsi-fungsi yang ada pada sistem yang dibangun.

Tabel 3 Pengujian Halaman Personel

\begin{tabular}{|l|l|l|}
\hline Aktivitas Pengujian & Realisasi Yang di Harapkan & Hasil \\
\hline Klik Halaman Login & Muncul Tampilan Login Admin & Sukses \\
\hline Klik Menu Home & Muncul Tampilan Utama & Sukses \\
\hline Klik Daftar Personel & Muncul Tampilan Data Personel & Sukses \\
\hline Klik Menu Keluagra & Muncul Tampilan Data keluarga & Sukses \\
\hline Ganti password & Muncul halaman ganti password & sukses \\
\hline Klik Halaman Keluar & Muncul tampilan keluar sistem & Sukses \\
\hline
\end{tabular}

Tabel 4 Pengujian Halaman Admin

\begin{tabular}{|l|l|l|}
\hline Aktivitas Pengujian & Realisasi Yang di Harapkan & Hasil \\
\hline Klik Halaman Login & Muncul Tampilan Login Admin & Sukses \\
\hline Klik Menu Home & Muncul Tampilan Utama & Sukses \\
\hline Klik Menu Dashboard & Muncul Tampilan Dashboard & Sukses \\
\hline Klik Menu Data Surat & Muncul Tampilan Menu Surat & Sukses \\
\hline
\end{tabular}




\begin{tabular}{|l|l|l|}
\hline Aktivitas Pengujian & Realisasi Yang di Harapkan & Hasil \\
\hline Kenaikan Gaji Berkala & Muncul tampilan Gaji Berkala & Sukses \\
\hline Perjalanan Dinas Mutasi & Muncul tampilan perjalanan dinas & Sukses \\
\hline Penetapan Status Gugur & Muncul tampilan penetapan status & Sukses \\
\hline Tanda Jasa & Muncul tampilan tanda jasa & Sukses \\
\hline Attribut & Muncul tampilan attribute sistem & Sukses \\
\hline Pangkat & Muncul tampilan data pangkat & Sukses \\
\hline Jabatan & Muncul tampilan data jabatan & Sukses \\
\hline Status & Muncul tampilan data status & Sukses \\
\hline Agama & Muncul tampilan data agama & Sukses \\
\hline Ganti password & Muncul halaman ganti password & sukses \\
\hline Klik Halaman Keluar & Muncul tampilan keluar sistem & Sukses \\
\hline
\end{tabular}

\subsection{Penerapan Program}

Penerapan atau Implementasi adalah proses penerapan rancangan program yang telah dibuat pada bab sebelumnya atau aplikasi dalam melaksanakan sistem informasi pemograman yang telah dibuat, hasil dari tahapan implementasi ini adalah suatu sistem pengolahan data yang sudah dapat berjalan dengan baik. Dengan demikian dapat diketahui apakah perangkat lunak ini dapat menghasilkan aplikasi sistem informasi yang sesuai dengan tujuan yang diharapkan. Implementasi perangkat lunak sistem informasi ini berbasis website dilakukan dengan menggunakan bahasa dan pemrograman PHP dengan basis data yang digunakan adalah MySQL.

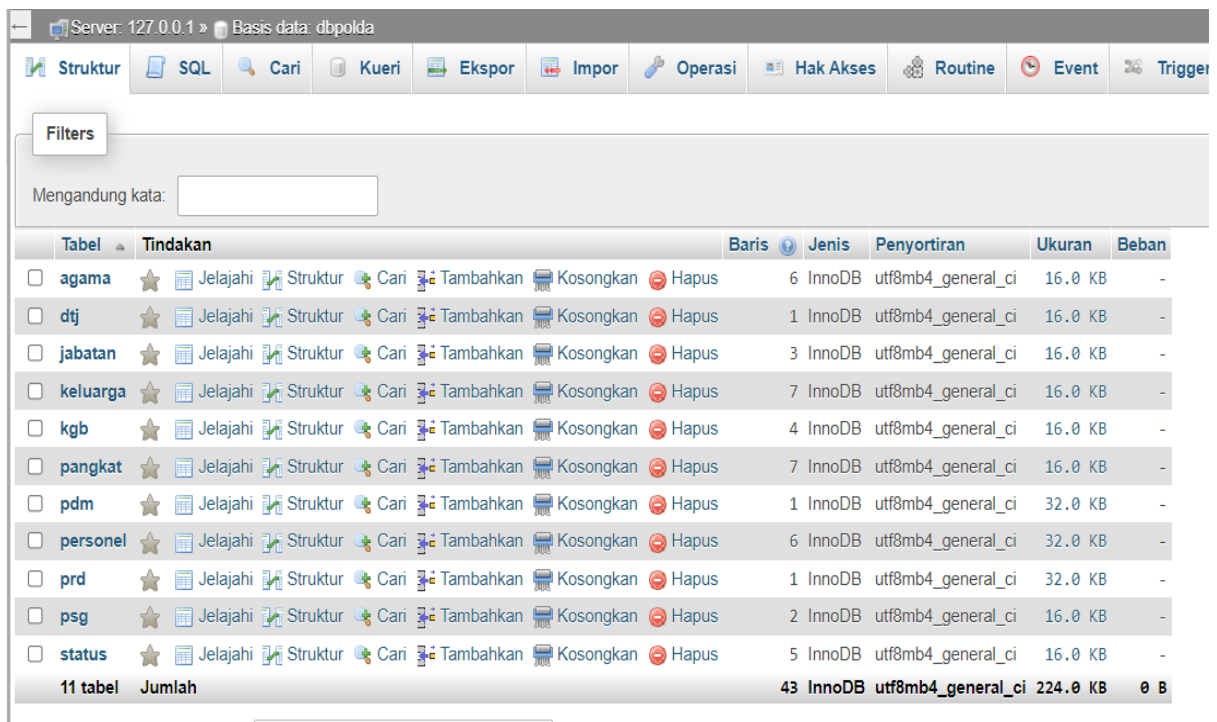

Gambar 8 Database Aplikasi Administrasi

Tabel 5 Penerapan Halaman Personel

\begin{tabular}{|l|l|l|}
\hline Menu & Deskripsi Nama File \\
\hline Halaman Login & $\begin{array}{l}\text { Halaman login untuk masuk } \\
\text { ke dalam sistem }\end{array}$ & /login.php \\
\hline Halaman Utama & $\begin{array}{l}\text { Halaman utama ketika } \\
\text { pengguna membuka aplikasi }\end{array}$ & /index.php \\
\hline Personel & $\begin{array}{l}\text { Halaman ini berisi tentang } \\
\text { data personel }\end{array}$ & /personel \\
\hline
\end{tabular}




\begin{tabular}{|l|l|l|}
\hline Keluarga & $\begin{array}{l}\text { Halaman ini beritas tentang } \\
\text { keluarga personel }\end{array}$ & $/ \mathrm{p}$-keluarga \\
\hline
\end{tabular}

Tabel 6 Penerapan Halaman Petugas

\begin{tabular}{|l|l|l|}
\hline Menu & Deskripsi & Nama File \\
\hline $\begin{array}{l}\text { Halaman Utama } \\
\text { Admin }\end{array}$ & $\begin{array}{l}\text { Halaman utama ketika pengguna } \\
\text { membuka aplikasi }\end{array}$ & admin/index.php \\
\hline User & $\begin{array}{l}\text { Halaman ini berisi tentang profil } \\
\text { admin }\end{array}$ & admin/user.php \\
\hline Personel & Halaman berisi data personel & /personel \\
\hline Keluagra & Halamana berisi data keluarga & /keluarga \\
\hline Surat & $\begin{array}{l}\text { Halaman ini berisi tentang layanan } \\
\text { administrasi surat }\end{array}$ & /personel \\
\hline $\begin{array}{l}\text { Kenaikan Gaji } \\
\text { Berkala }\end{array}$ & Kenaikan gaji bekala & Kgb \\
\hline $\begin{array}{l}\text { Perjalanan Dinas } \\
\text { Mutasi }\end{array}$ & Perjalanan dinas mutas & Pdm \\
\hline $\begin{array}{l}\text { Penetapan Status } \\
\text { Gugur }\end{array}$ & Status guru & Psg \\
\hline Tanda Jasa & Tanda jasa & ts \\
\hline Attribute & Halaman ini berisi attribute sistem & /personel \\
\hline Pangkat & $\begin{array}{l}\text { Halaman ini beritas attribute } \\
\text { pangkat }\end{array}$ & /pangkat \\
\hline Jabatan & $\begin{array}{l}\text { Halaman ini berisi attribute } \\
\text { jabatan }\end{array}$ & /jabatan \\
\hline Status & Halaman ini berisi attribute status & /status \\
\hline Agama & Halaman ini berisi attribute agama & /agama \\
\hline
\end{tabular}

Penerapan penggunaan program sistem informasi administrasi di Bagwatpers Biro SDM Polda Kepri terbagi pada dua antar muka, antar muka pengguna Personel dan antar muka admin/petugas di Bagwatpers Biro SDM Polda Kepri.

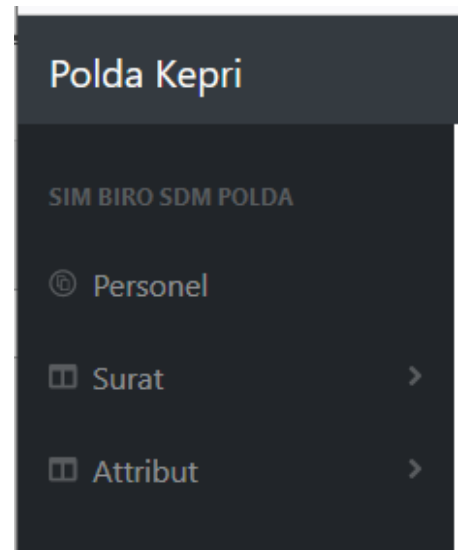

Gambar 9 Personel- Menu Aplikasi 


\begin{tabular}{|c|c|c|c|c|}
\hline $\bar{\Xi}$ Polda Kepri & $x$ & + & & \\
\hline
\end{tabular}

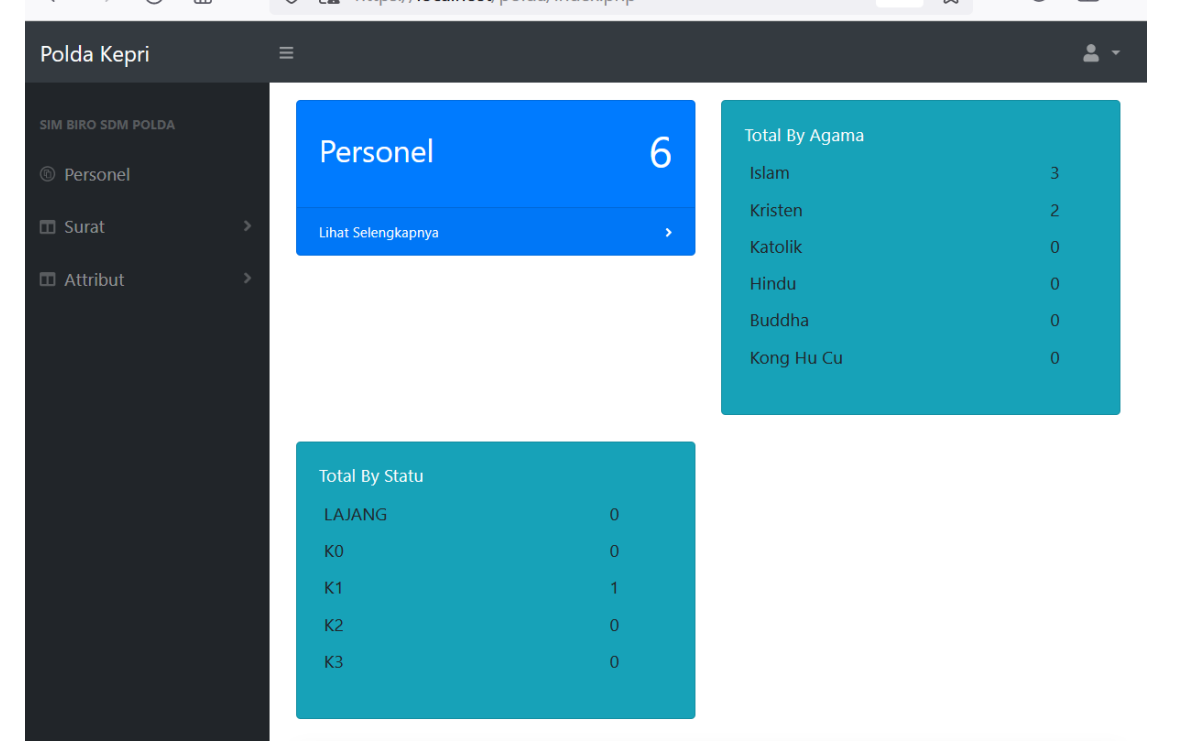

Gambar 10 Petugas - Menu Aplikasi

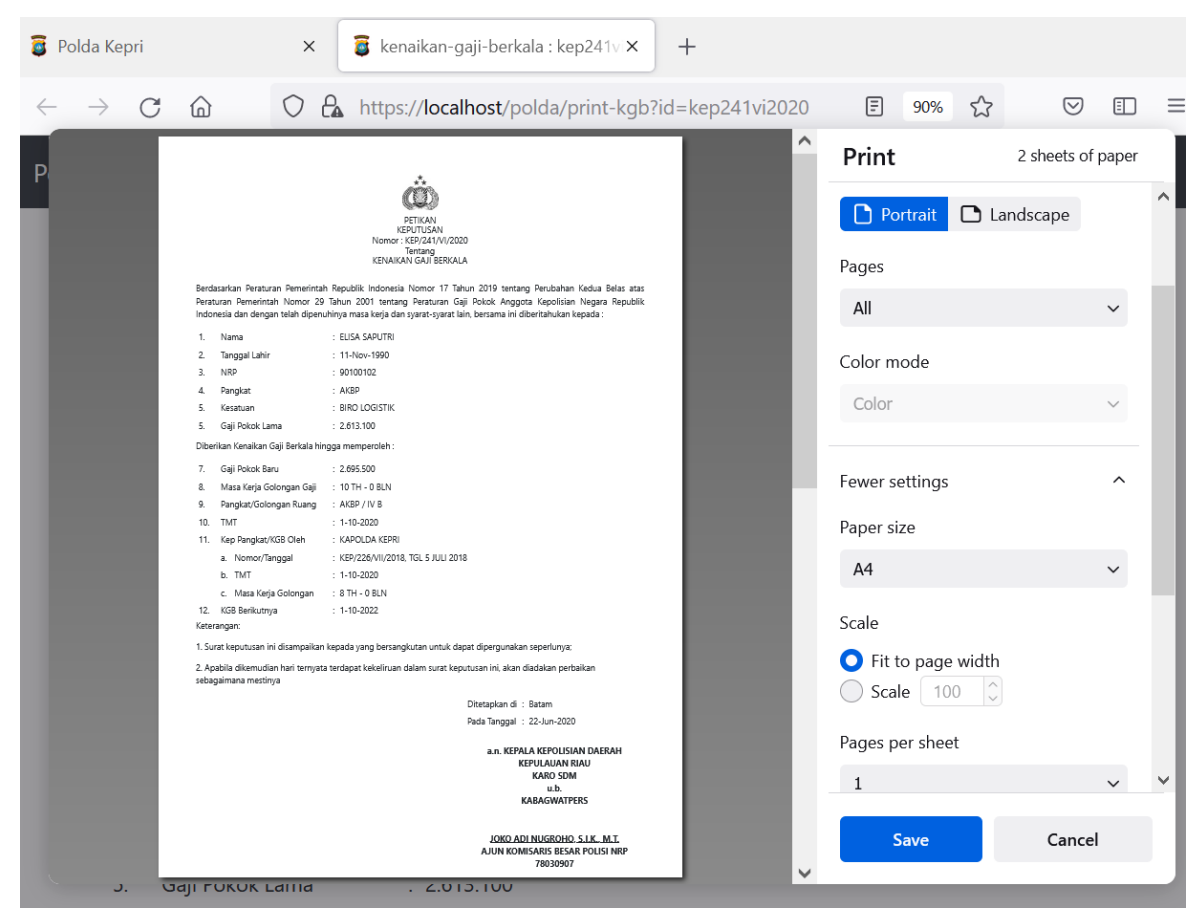

Gambar 11 Petugas - Gaji Berkala 


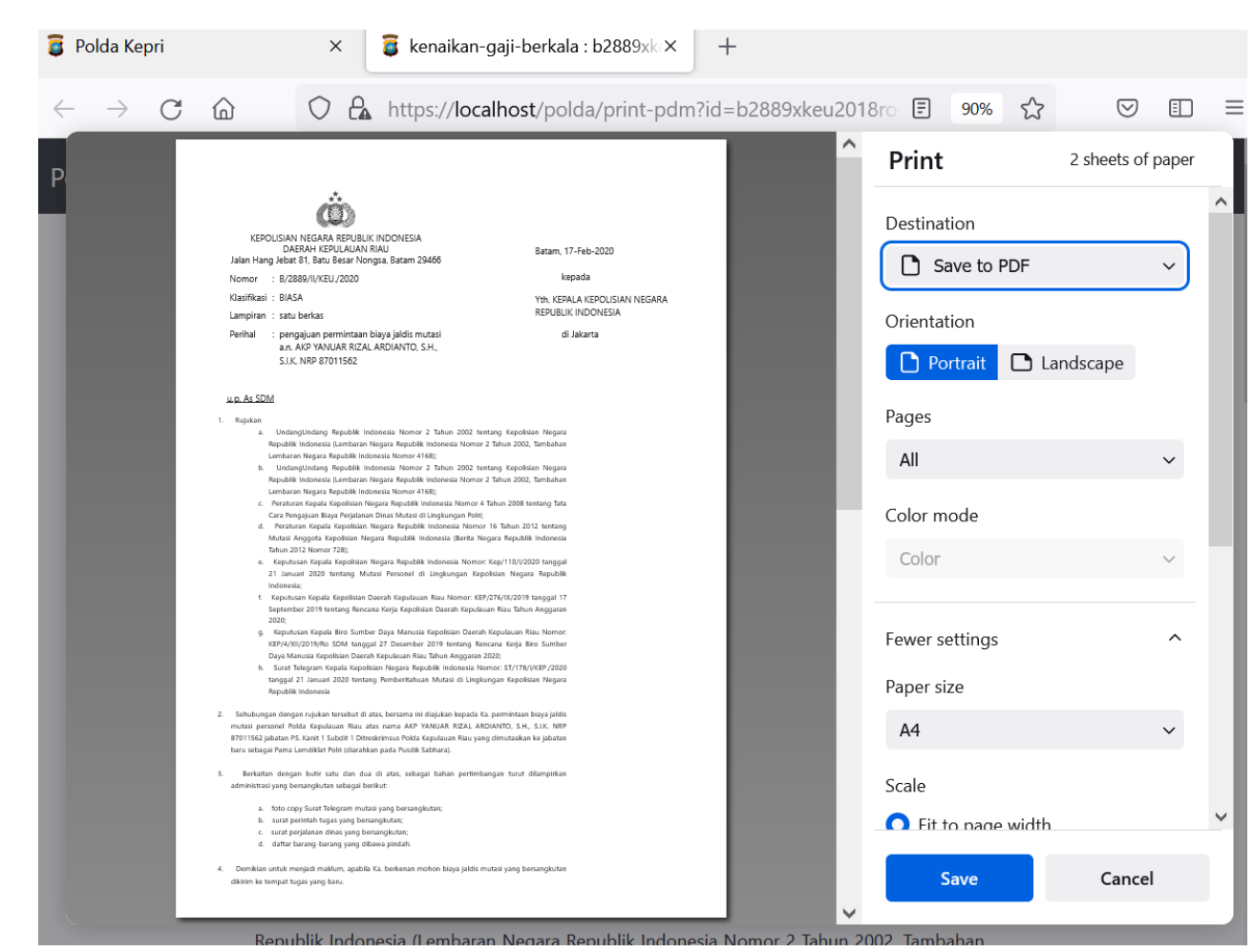

Gambar 12 Petugas - Perjalanan Dinas Mutasi

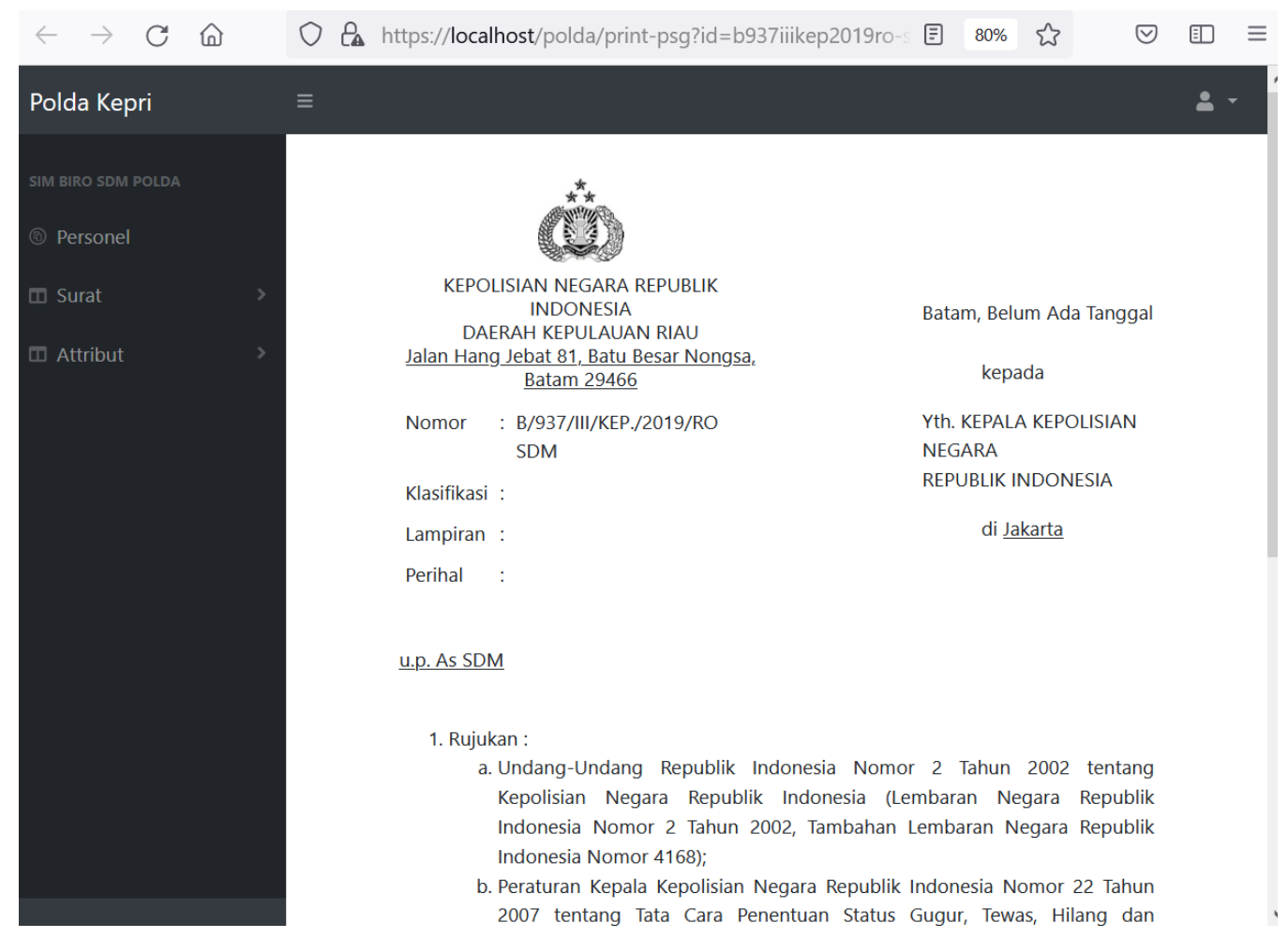

Gambar 13 Petugas - Pengantar Status Gugur 


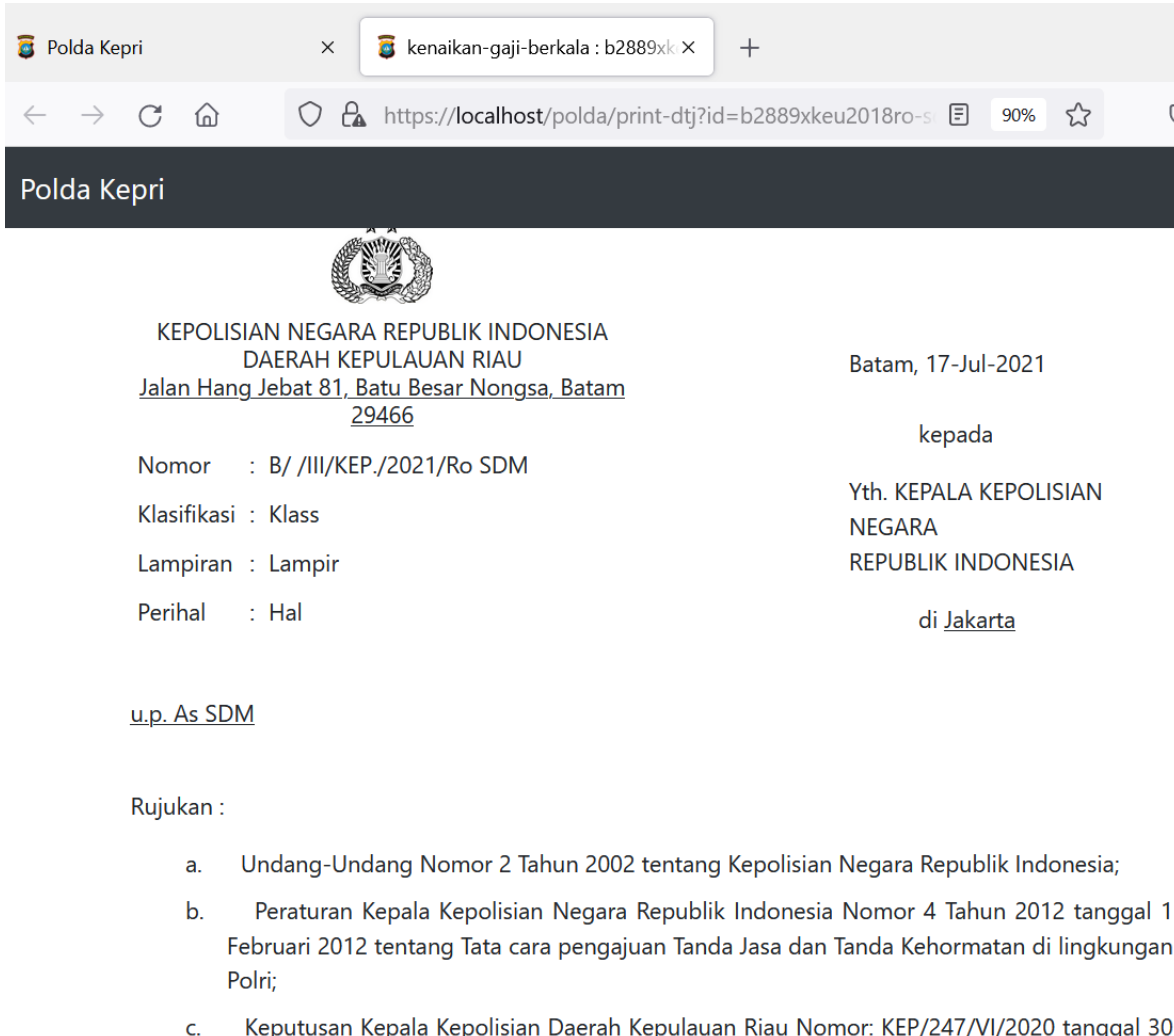

\section{Gambar 14 Petugas - Pengantar Tanda Jasa}

\begin{tabular}{|c|c|c|c|c|c|}
\hline ฮె Polda Kepri & $x$ & ฮె kenaikan-gaji-berkala : b669iike $\times$ & + & & \\
\hline$\leftarrow \rightarrow$ C & 0 & https://localhost/polda/print-prd & d=b669iikep2021ro-s 国 & $90 \%$ & 国 \\
\hline
\end{tabular}

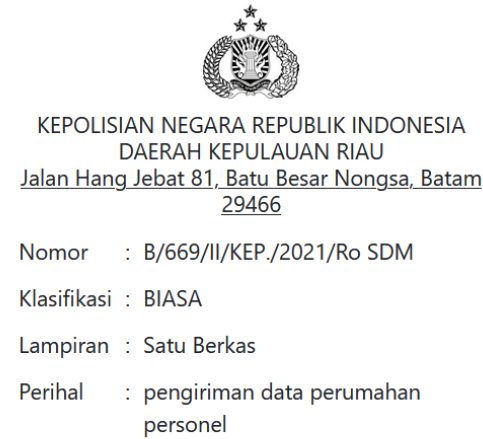

u.p. As SDM

1. Rujukan :

b. Peraturan Pemerintah Nomor 42 Tahun 2010 tentang Hak-Hak Anggota Kepolisian Negara Republik Indonesia;

Gambar 15 Petugas - Pengantar Penempatan Rumah Dinas 


\section{KESIMPULAN}

Dari semua aspek yang telah diterangkan dan sampai pada hasil penelitian pada "sistem informasi administrasi di Bagwatpers Biro SDM Polda Kepri

1. Membangun dan merancang sebuah aplikasi sistem informasi administrasi di Bagwatpers Biro SDM Polda Kepri membutuhkan pengambilan data yang rinci pada saat observasi sehingga hasil dari aplikasi yang berjalan dapat memenuhi kebutuhan petugas. Serta betapa pentingnya sistem informasi administrasi untuk mendukung kesan bahwa sistem berjalan dengan baik, sehingga petugas terbantu dalam pengelolaan data kenaikan gaji berkala Personel polda kepri dan jajaran, biaya perjalanan dinas mutasi, penetapan status gugur, tewas dan meninggal dunia biasa Personel, pemenuhan perumahan bagi Personel polda kepri dan jajaran dan tanda jasa dan tanda kehormatan Personel

2. Penerapan pada aplikasi yang dibuat dan dirancang telah berhasil dilakukan dan sangat membantu juga memberikan kesan yang canggih dan update dengan mengikuti perkembangan teknologi di zaman modern seperti saat ini

\section{SARAN}

Berdasarkan hasil penelitian ini ada beberapa saran yang penulis usulkan untuk mengembangkan sistem agar menjadi lebih baik, diantaranya sebagai berikut:

1. Untuk mendukung sistem yang ada maka diperlukan peningkatan sumber daya manusia, yaitu sumber daya dalam pengoperasian sistem dan mampu merawat, memelihara sistem tersebut dengan baik

2. Aplikasi yang ada dapat ditambahkan untuk menjadi lebih lengkap dalam bentuk dashboard namun membutuhkan waktu yang tidak singkat.

\section{PUSTAKA}

1) Aulia, M. R., Aksad, H., \& Eka, C. K. (2017). Sistem Informasi Administrasi Pelayanan Publik Intelkam Polres Hulu Sungai Selatan Berbasis Web. Jutisi: Jurnal Ilmiah Teknik Informatika Dan Sistem Informasi, 5(1), 943-954.

2) Cen, C. (2020). Tinjauan Yuridis Terhadap Efektivitas Pelaksanaan Fungsi Bhayangkara Pembina Keamanan Dan Ketertiban Masyaratakat (Bhabinkamtibmas) Dalam Wilayah Hukum Kepolisian Daerah Kepulauan Riau. Journal Of Chemical Information And Modeling, 5(2), 29-45.

3) Dedi, Iqbal, M., \& Fahroji, W. (2019). Sistem Informasi Administrasi Kependudukan Berbasis Web Di Kelurahan Sangiang Jaya. Seminar Nasional Aptikom (Semnastik) 2019, 306-313.

4) Ropianto, M. (2016). Pemahaman Penggunaan Unified Modelling Language. Jt-Ibsi, $1(1), 43-50$.

5) Ropianto, M., Rukun, K., Hayadi, B. H., \& Durachman, Y. (2020). Utilization Of Information System Dashboard Of Internal Quality Guarantee At Stt-Ibnu Sina Batam. 63(3), 946-956.

6) Setiawan, D. (2017). Buku Sakti Pemrograman Web: Html, Css, Php, Mysql \& Javascript. Anak Hebat Indonesia.

7) Solichin, A. (2016). Pemrograman Web Dengan Php Dan Mysql. Budi Luhur.

8) Sulistiyarini, D., \& Sabirin, F. (2018). Analisis Perancangan Sistem Informasi Administrasi Program Studi Pendidikan Teknologi Informasi Dan Komunikasi. Jurnal Penelitian Dan Pengembangan Sains Dan Humaniora, 2(1), 22. 